\title{
Morphology and Anatomy of the Fused Vein Trait in Cucurbita pepo L.
}

\author{
R. Bruce Carle and J. Brent Loy \\ Department of Plant Biology, University of New Hampshire, Durham, NH 03824
}

Additional index words. leaf development

\begin{abstract}
The morphology, growth rate and anatomy of the fused vein trait were characterized in Cucurbita pepo using the inbreds NH2405 (fused vein), NH7210 (moderately fused vein), and NH614 (normal). Morphological analysis showed that the trait is characterized by a partial fusion of the five primary leaf veins. Fusion begins at the distal point of the petiole and extends along the central vein. Branching of the veins is delayed and there is a reduction of the interveinal leaf blade. Consequently, the upper leaf surface appears puckered or wrinkled. Depending on genetic background, the onset of fused vein leaf production starts at the fourth to tenth leaf stage and continues throughout vegetative growth. The extent of fusion increases with leaf number but stabilizes by the twentieth leaf stage maximum extent of vein fusion also varies with genetic background $(5-20 \mathrm{~cm})$. Though fused vein and normal inbreds differed in the rate and pattern of leaf growth, examination of $\mathrm{F}_{2}$ and $\mathrm{BC}$ populations revealed no significant effect of the fused vein trait on leaf number, leaf size, and rate of leaf initiation. Anatomical examination revealed different vascular patterns in the transition zone between petiole and leaf blade for normal and fused vein leaves. In normal leaves, the vascular bundles of the petiole enlarge and coalesce to form a vascular crescent. The crescent reorganizes and diverges as large vascular columns and pairs of smaller flanking vascular bundles into each vein. In contrast, two cycles of enlargement, coalescence, and dispersal occur in fused vein leaves.
\end{abstract}

As a species, Cucurbita pepo displays considerable variation in vegetative structures (Whitaker and Davis, 1962). Mature plants range from compact, single-stem bushes to rambling, multi-stem vines. Juvenile leaves are frequently three-lobed, while mature leaves have five shallow to deep lobes with narrow to wide sinuses. Leaves also show subtle variation in leaf size, trichome harshness, and surface mottling. However, only two genes affecting leaf structure have been reported. The dominant gene mottled, $M$, produces silver gray areas in the axils of leaf veins (Scarchuk, 1954). The recessive gene rosette, ro, imparts a spiraled appearance to the lower leaf lobes (Mains, 1950).

A new $C$. pepo mutant leaf form, fused vein (FV), has shown potential as a roguing marker for hull-less seeded pumpkin cultivars (Carle and Loy, 1991). The trait was first observed in 1987 among segregating material descending from a cross between 'Tricky Jack' and 'Minijack'. It has since been fixed in two hullless seeded inbred lines, NH2405 and NH7210. In both lines, it is expressed before flowering and imparts a distinctive, conspicuous leaf morphology. The trait is rare and inherited stably (Carle and Loy, 1996a). Limiting its use to hull-less material can provide outcross detection from hulled contaminants.

The purpose of this study was to characterize the morphology and anatomy of the FV trait and to determine its role in leaf development. Using selected breeding lines, the extent and stability of the FV phenotype were ascertained as well as its effect on general growth rate.

\section{Materials and Methods}

Plant material. Three hull-less seeded $C$. pepo breeding lines developed at the Univ. of New Hampshire were used for the study. The inbred line NH2405 served as the archetype for the FV phenotype. The related moderately fused line NH7210 provided

Received for publication 23 Jan. 1995. Accepted for publication 10 July 1995. Scientific contribution no. 1890 from the New Hampshire Agricultural Experiment Station, Durham. The cost of publishing this paper was defrayed in part by the payment of page charges. Under postal regulations, this paper therefore must be hereby marked advertisement solely to indicate this fact. additional information on expression. Both lines were compared to the normal $(\mathrm{N})$ phenotype displayed by the inbred line NH614.

Morphological study. FV and $\mathrm{N}$ plants were examined in field plots used for inheritance and pollen competition studies during 1990,1991, and 1992 at the Woodman Horticultural Farm, Durham, N.H. (Carle and Loy, 1996a, 1996b). Plots of Charlton sandy loam were supplied with 80 to $120 \mathrm{~kg} / \mathrm{ha} \mathrm{N}-\mathrm{P}-\mathrm{K}$, based on soil tests before broadcast application. Nonchemical weed control and supplemental irrigation were given as needed. Disease and insects were controlled with recommended pesticides. Lines in all plots were planted in adjacent rows $1.8 \mathrm{~m}$ apart with $0.6 \mathrm{~m}$ between plants. In all cases, plant growth and development were typical for fieldgrown C. pepo. Over the 3-year period, 249 NH2405, 293 NH614, and 148 NH7210 plants were examined throughout growth for the initiation of fused vein leaves and the extent of vein fusion. Additionally, in a 1991 pollen competition field plot, the length of vein fusion from the distal end of the petiole to divergence of the inner lateral veins was measured for the first 20 leaves borne on the main stem of 10 randomly selected NH2405 plants.

Plant growth study. $\mathrm{NH} 2405$, NH614, their $\mathrm{F}_{1}$ hybrid, $\mathrm{F}_{2}$, and FVBC generations were used to examine the association of the FV trait with plant growth. On 22 Jan. 1992, in the UNH greenhouse, eight 9.5-liter pots were sown with two seeds each, for both the inbreds and $F_{1}$ hybrid. Twelve pots (two seeds each) were used for both the $\mathrm{F}_{2}$ and FVBC generations. After 1 week, each pot was thinned to one plant. In the third week, eight plants were selected for the $\mathrm{F}_{2}$ and FVBC generations to achieve a balance of phenotypes $\left(\mathrm{F}_{2}: 3 \mathrm{FV}\right.$ and $5 \mathrm{~N}$; FVBC: $4 \mathrm{FV}$ and $4 \mathrm{~N}$ ). All plants received the same cultural treatments, including Premix soil-less medium, periodic feeding with water soluble fertilizer (Peters 20-20-20) and pest control (Safer soap). Emerging lateral stems were removed to compare absolute apical growth.

Beginning with the second week of growth, the number of unfolded leaves, total leaf area, and leaf phenotypes were determined for each plant at weekly intervals for 4 weeks. A leaf was considered unfolded when it reached a width of $2.5 \mathrm{~cm}$. Total leaf area was calculated as the sum of individual leaf area estimates. Individual estimates were determined by multiplying a blade's greatest width by its length from tip to petiole. Accumulated leaf 
numbers and areas for the different genotypes were compared using linear regression analysis.

The method for leaf area estimation was derived by sampling twenty leaves ranging in size and genotype at the conclusion of the study. They were measured, removed, flattened, and photocopied. The photocopy images were cut from paper and weighed. An area by weight ratio for the paper was used to convert image weights into leaf areas. The photocopy areas were compared to width by length estimates using linear regression analysis. An $R^{*}$ value of 0.99 indicated multiplication without a correction factor was an adequate method for leaf area determination.

Anatomical study. Tissue samples of NH2405 and NH614 were collected from randomly selected field-grown plants at the Woodman Horticultural Farm, in mid-August 1991. Samples consisted of the distal $3-5 \mathrm{~cm}$ of either a main or lateral stem, including all attached leaves and flower buds. They were preserved in Carnoy's Solution (75\% absolute ethanol, $25 \%$ glacial acetic acid) and stored for later analysis.

Standard histological procedures were employed as outlined by Jensen (1962). Leaves, petiole and blade combined, about $1 \mathrm{~cm}$ long, with clearly visible venation patterns were selected and dissected from the tissue samples. They were dehydrated in an ethyl and tertiary butyl alcohol series, imbedded in paraffin, and serially cross sectioned at $14 \mu \mathrm{m}$ using a rotary microtome. Sections from five good series were obtained for each genotype, affixed to glass slides using Haupt's adhesive, deparaffinized, stained with safranin and fast green, and mounted with Canada balsam. $\mathrm{N}$ and FV sections were compared microscopically for differences in vein structure and vascular distribution.

\section{Results and Discussion}

Morphological description. The FV phenotype of NH2405 is characterized by a partial fusion of the five primary leaf veins: a central vein, two outer laterals, and two inner laterals (Fig. 1). Fusion begins at the distal point of the petiole and extends to more than half the length of the leaf blade. Initially, all five veins are united; the outer laterals diverge first into the lower leaf lobes, followed by the inner laterals into the upper lobes. Although the veins are joined, they are visibly distinct.

Production of FV leaves begins with the fourth leaf stage and continues throughout vegetative growth. The extent of fusion varies with leaf number (Fig. 2). It is moderate in early leaves (5 $\mathrm{cm})$, is pronounced by the tenth leaf stage $(10 \mathrm{~cm})$, and becomes stabilized and extensive by the sixteenth to twentieth leaf stage ( 15 $\mathrm{cm}$ ). With extensive fusion, several secondary veins are fused to the central and primary veins. The interveinal leaf blade is also reduced and the upper leaf surface appears puckered or wrinkled. Consequently, the FV trait confers a distinctive appearance to juvenile and mature plants when compared to the $\mathrm{N}$ phenotype.

The pattern of vein fusion was the same for all NH2405 plants regardless of the plot examined. Observation of NH7210, however, revealed that FV morphology varies with genetic background. In NH7210, vein fusion begins similarly at the fourth leaf stage and increases in magnitude, but it is never as extensive as in NH2405. Leaf size may be a contributing factor; NH7210 has smaller leaves than NH2405. Similar phenotypic variation was also noticed among $\mathrm{F}_{2}, \mathrm{~F}_{3}$, and $\mathrm{FVBC}$ populations generated between NH2405 and NH614 for inheritance studies (Carle and Loy, 1996a). The onset of FV leaf production ranged from the fourth to the tenth leaf stage and the maximum extent of vein fusion varied from $5-20 \mathrm{~cm}$. The greatest fusion occurred in plants with the earliest onset of FV leaves and the deepest leaf lobes.

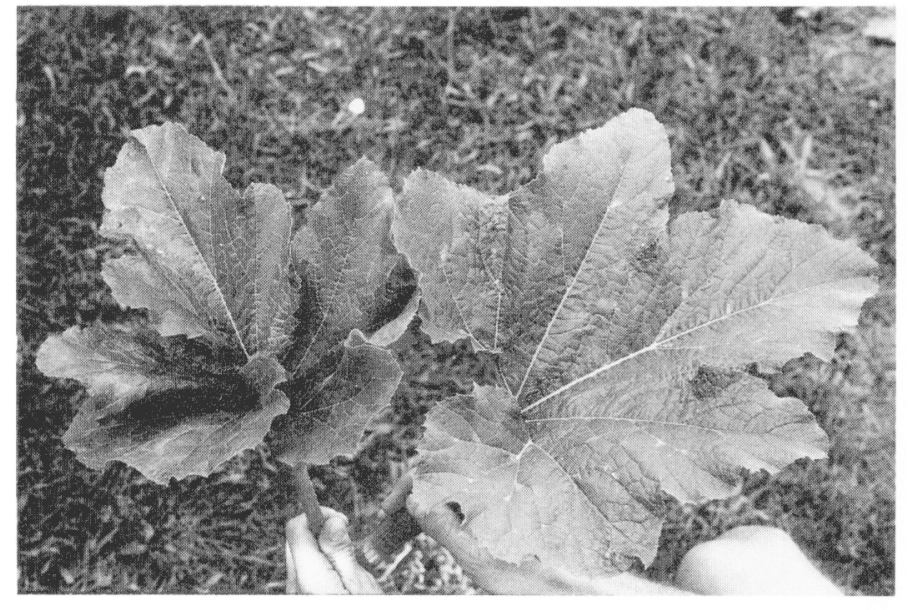

A

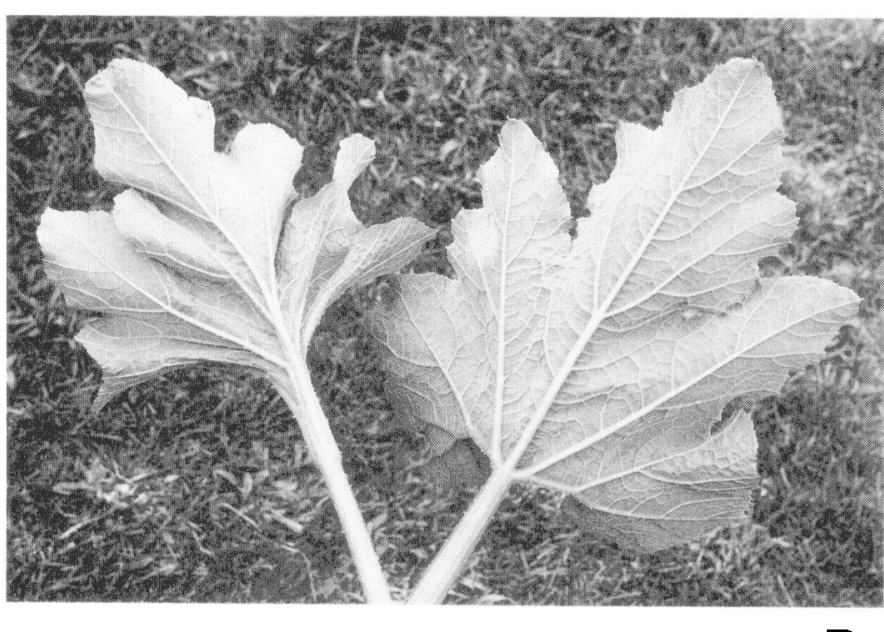

B

Fig. 1. Fused vein and normal leaf comparison, adaxial (A) and abaxial (B) views.

There were no other unusual morphologies associated with this trait. Stem fascination and female flower cohesion, found in some C. pepo lines, were both absent. The subtending leaf of distillate flowers in NH2405 is occasionally fused to the flower's pedicel and ovary, but this has been observed by the authors in other $\mathrm{N}$ inbred lines.

Plant growth rate. Field observations suggested that the FV trait may affect general growth rate. The plant habit of NH2405 is open and typically smaller than NH614 and many C. pepo bush cultivars. It is dominated by a strong main stem with two secondary lateral stems. In contrast, NH614 is vigorous with dense foliage and multiple stems. The FV trait is also a gametophytic subvital (Carle and Loy, 1996b). An association between gametophytic subvitality and reduced plant size, and vigor has been demonstrated in several species: Zea mays (Mulcahy, 1974; Ottaviano et al., 1983), Dianthus chinensis (Mulcahy and Mulcahy, 1975), Petunia hybrida (Mulcahy et al., 1975), Medicago sativa (Mulinix and Iezzoni, 1988), and C. pepo (Windsor et al., 1987).

The results of the greenhouse growth study challenge this supposition for the FV trait. Leaf number and total leaf area increased logarithmically with time for all genotypes, NH2405, NH614 $(\mathrm{NH} 2405 \times \mathrm{NH614}) \mathrm{F}_{1}$, and both $\mathrm{F}_{2}$ and BC plants, independent of leaf phenotype. Following logarithmic transformation, 


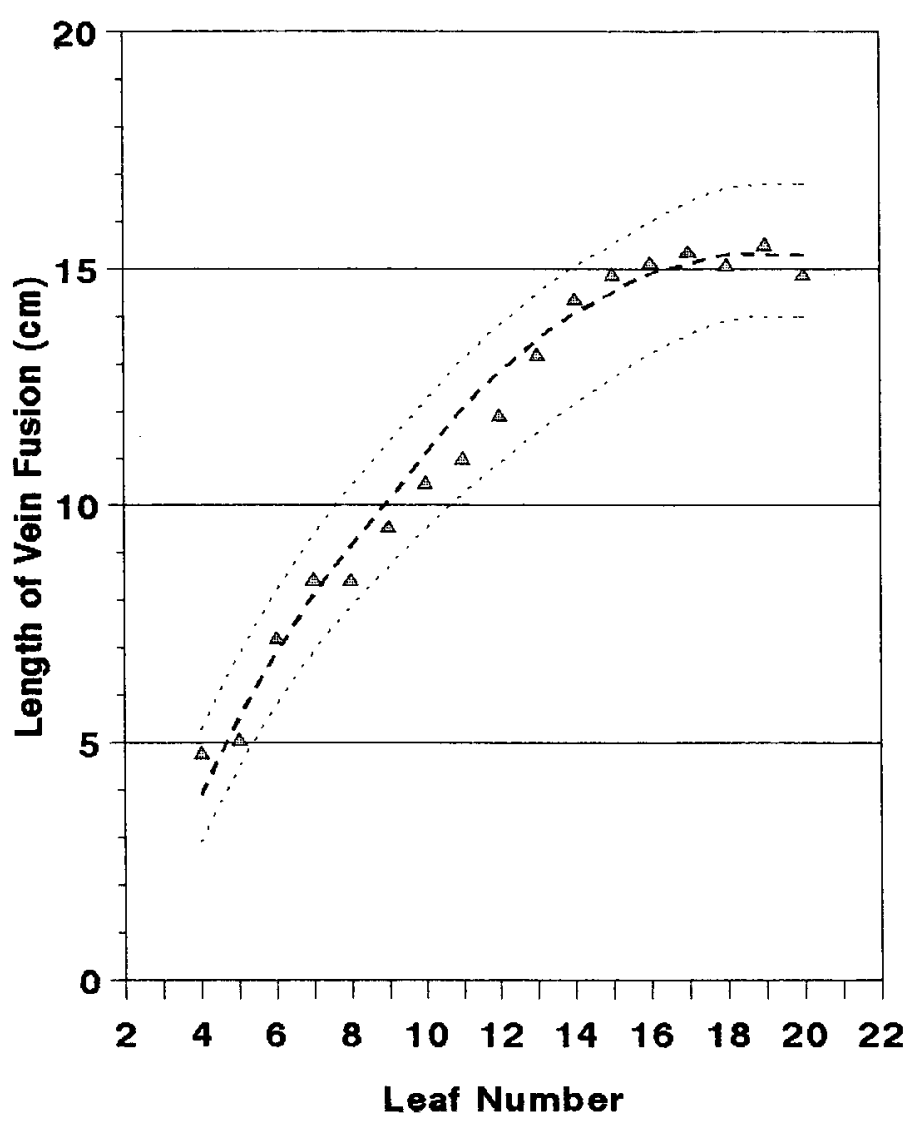

Fig, 2. Length of vein fusion by leaf number for Cucurbito pepo inbred NH2405. Measurements were made of the first twenty leaves for ten plants, Each data point represents a mean value. Dotted lines represent $95 \%$ confidence interval.

simple linear regression models fit both growth measurements with high correlation for all genotypes $\left(R^{2}=0.95-0.99\right)$. The slopes did not differ significantly across genotypes for either leaf number or area, indicating a common basal growth rate for all genotypes $(\mathrm{F}$ values of 0.28 and 0.0013 , respectively for 8 and 18 degrees of freedom).

The field observations of $\mathrm{NH} 2405$ are explained by comparison of the FV, N, and F, regression lines (Fig. $3 \mathrm{~A}$ and B). In the first 2 weeks of growth during seedling development, the rate of early leaf initiation was slower in the FV inbred, resulting in fewer accumulated leaves throughout the growth study. NH2405 leaves, however, were larger than the N leaves of NH614 and resulted in the same total leaf area. The F, displayed heterosis. It produced the same number of leaves as the $\mathrm{N}$ line, but with a larger size, yielding a higher total leaf area.

Comparison of the FV and $\mathrm{N}$ phenotypes in the $\mathrm{F}_{2}$ and FVBC generations revealed no significant differences in growth between the phenotypes (Fig. $3 \mathrm{C}-\mathrm{F}$ ). Although both FV and $\mathrm{N}$ individuals showed various combinations of leaf size and number, rate of leaf initiation, leaf size, and leaf number were independent of leaf morphology. Additionally, $\mathrm{FV}$ segregants in $\mathrm{F}_{2}$ and $\mathrm{F}_{3}$ inheritance populations have shown no association between leaf morphology and stem production. FV plants ranged from single stem to multiple stems.

Anatomical description. For N and FV genotypes, the sectioned $1 \mathrm{~cm}$ length leaves, petiole and blade combined were miniature versions of fully expanded leaves, complete in form and organization but still in the processes of lamina expansion and tissue development. The areolar areas (regions between veins) of the lamina were the least developed, consisting of protoderm, adaxial (upper), middle, and abaxial (lower) mesophyll layers. There was no differentiation of palisade and spongy mesophyll cells, stomata, and trichomes. Minor vein development had begun, with procambial traces appearing in swellings of the middle mesophyll layer. In contrast, development of the vasculature in the petioles and primary and secondary veins was extensive. The arrangement and bicollateral organization of the vascular bundles were evident as were protophloem, protoxylem and bundle sheath cells. Unlike the interveinal areas, trichomes were present on the petiole and vein surfaces and strands of presumptive collenchyma were observed. The absence of safranin staining, however, indicated no signification had occurred.

The arrangement of vascular tissue in the petioles of $\mathrm{N}$ and FV leaf sections was similar and consistent with previous anatomical studies of C. pepo (Metcalfe and Chalk, 1950; Whitaker and Davis, 1962). At the base of the petiole there is a ring of thirteen vascular bundles, twelve in pairs and one abaxial, unpaired bundle. At the top of the petiole, pairing of the bundles ceases and two to three of the adaxial bundles divide into two. As the bundles enter the transition zone between petiole and leaf blade, they enlarge and coalesce before separating into the five primary leaf veins. The pattern of coalescence and 'divergence, however, and the final number of bundles in each primary vein differ between $\mathrm{N}$ and $\mathrm{FV}$ leaves (Figs. 4 and 5).

In $\mathrm{N}$ leaves, vascular bundles in the abaxial half of the petiole expand and merge, forming a crescent of vascular tissue as they enter the transition zone (Fig. 4 B3, and D). Invagination of the epidermis and cortex defines and eventually separates the individual leaf veins (Fig. 4 B4, B5, F, G, H, and I). As flanking bundles enlarge and join the crescent, the crescent reorganizes (Fig. 4E). Three large distinct vascular bundles develop within the lower and outer portion of the crescent and then diverge into the central and inner lateral veins (Fig 4 B4, F, and G). The adjoined flanking vascular strands also form large bundles that diverge abruptly into the two outer lateral veins (Fig. 4 B4, B5, H, and I). As the five large bundles diverge and assume abaxial positions in each vein, the vascular crescent is partially split (Fig. 4F). Consolidation of the remaining vascular tissue and the convergence of additional adaxial bundles forms a stelliform vascular complex, occupying the upper half of the transition zone (Fig. 4 B5, and G). From the edges of the complex, individual bundles diverge in pairs into the leaf veins (Fig 4 B5, B6, H, and I). With completion of invagination, the central and lateral veins contain a large vascular bundle flanked by six or eight smaller vascular bundles, respectively (Fig 4 B7, J, and $\mathrm{K})$. As each leaf vein branches into pairs of successive secondary veins, the most adaxial bundles diverge into the secondaries until finally, the large abaxial bundles themselves divide and diverge into the most distal secondaries.

In the FV line, the vascular bundles do not completely coalesce to form a crescent (Fig. $5 \mathrm{D}$ and $\mathrm{E}$ ). The abaxial bundle of the petiole remains partially distinct, surrounded by parenchyma cells. As invagination begins, this bundle diverges into the central leaf vein by itself, leaving a bipolar complex of vascular tissue (Fig. 5 B4 E, and F). As flanking bundles merge with the complex, the complex gravitates to the upper half of the transition zone, reorganizes and then rapidly disassociates (Fig. $5 \mathrm{~F}, \mathrm{G}$, and $\mathrm{H}$ ). As in the $\mathrm{N}$ line, pairs of vascular bundles diverge into the central vein. The first pair eventually unites with the abaxial bundle to form the central vein's large vascular bundle (Fig. 5 B5, B6, F, G, H, and I). Unlike the $\mathrm{N}$ line, the vascular tissue destined for the lateral veins disperses as a partial ring of bundles around the periphery of the upper transition zone (Fig. $5 \mathrm{H}$ and I). The most adaxial of these 

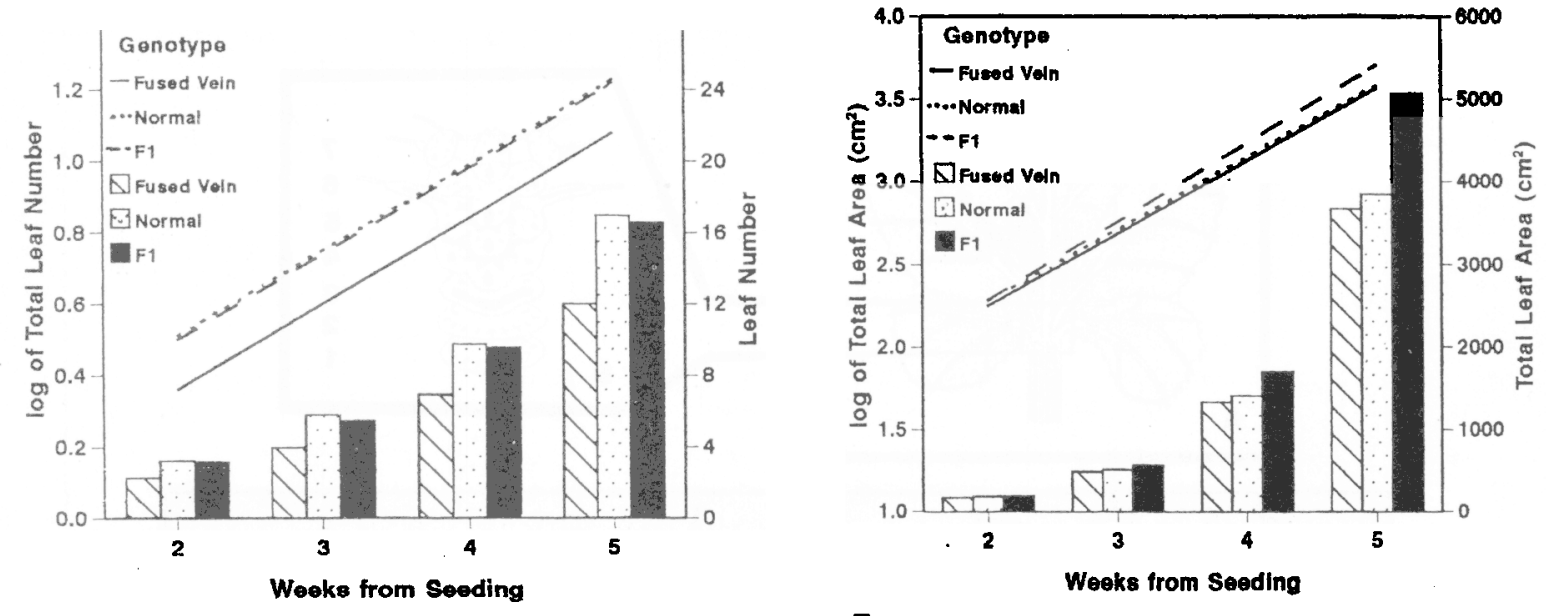

C

D
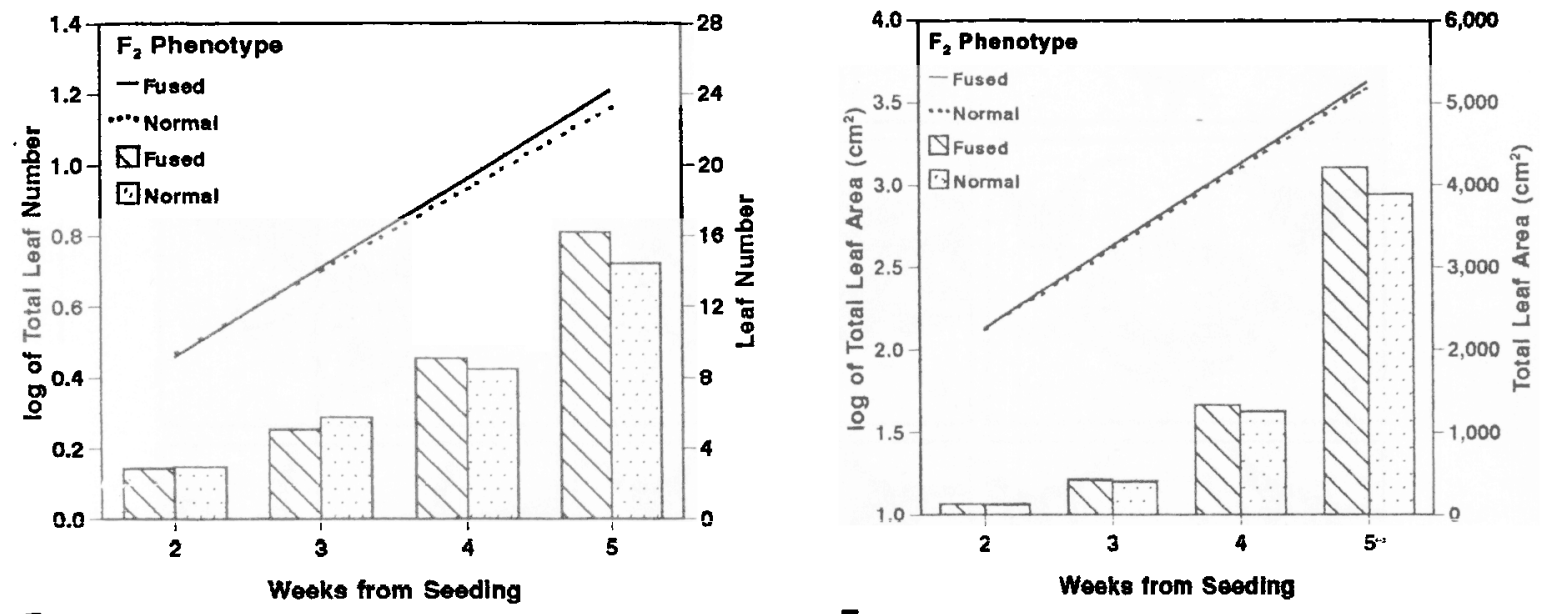

E

$\mathbf{F}$
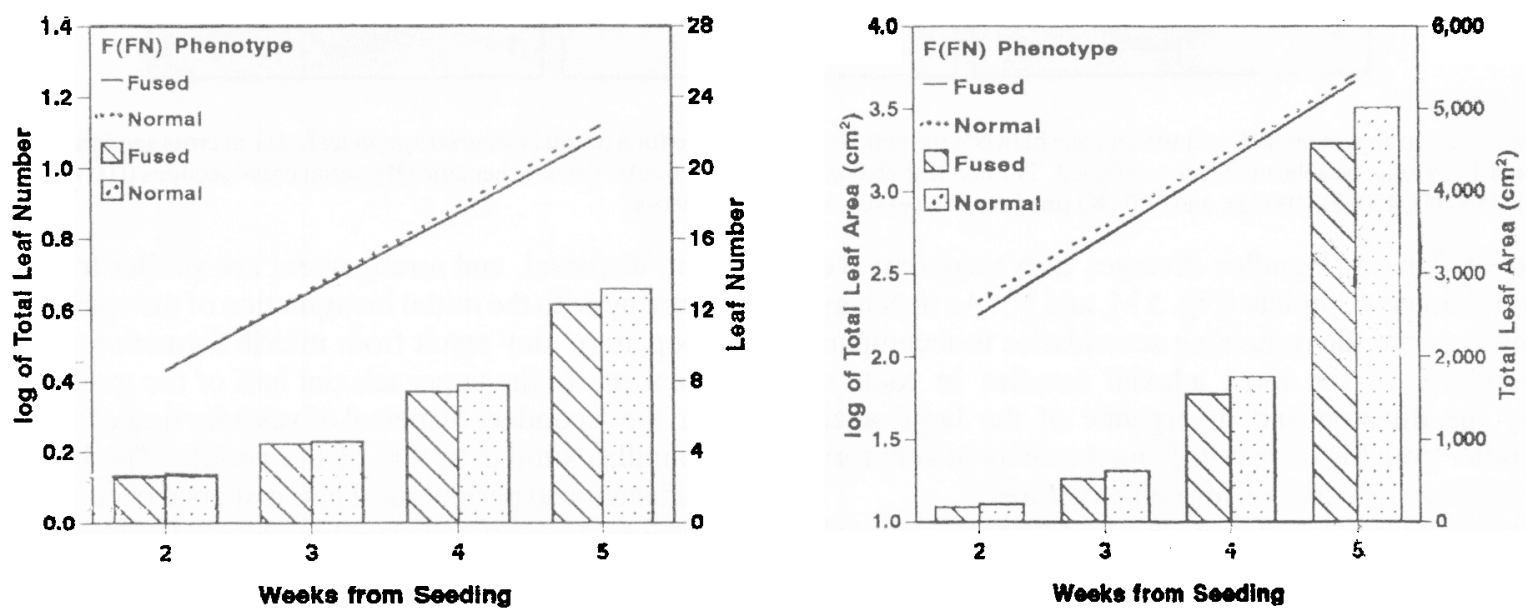

Fig. 3. Effect of leaf genotype and phenotype on plant growth rate in parental and $F_{1}(A$ and $B), F_{2}(C$ and $D)$, and $B C(E$ and $F)$ generations. NH2405 served as the fused vein parent and NH614 served as the normal leaf parent. Subcharts A, C, and E show mean values for accumulated leaf numbers. Subcharts B, D, and F show mean values for accumulated total leaf areas.

bundles diverge into the secondary veins of the lower leaf lobes before the outer lateral veins form (Fig. $5 \mathrm{I}$ and J). Bundle division and a second coalescence phase sort the remaining peripheral bundles into the outer and inner lateral veins. As invagination begins to separate the outer lateral veins, large peripheral bundles become the vascular bundles in the inner and outer laterals (Fig. 5 B7, B8, I, and J). The flanking pairs of smaller bundles in the outer laterals arise from the division of both adaxial bundles and large bundles at the points of invagination (Fig. $5 \mathrm{I}, \mathrm{J}$, and K). Once the outer lateral veins separate, flanking bundles in the central and inner lateral veins reconverge and form two secondary complexes of vascular tissue (Fig. 5L). .These complexes reorganize and then generate pairs of flanking bundles that diverge back into the veins as invagination completes vein separation (Fig. 5M). Typically, 

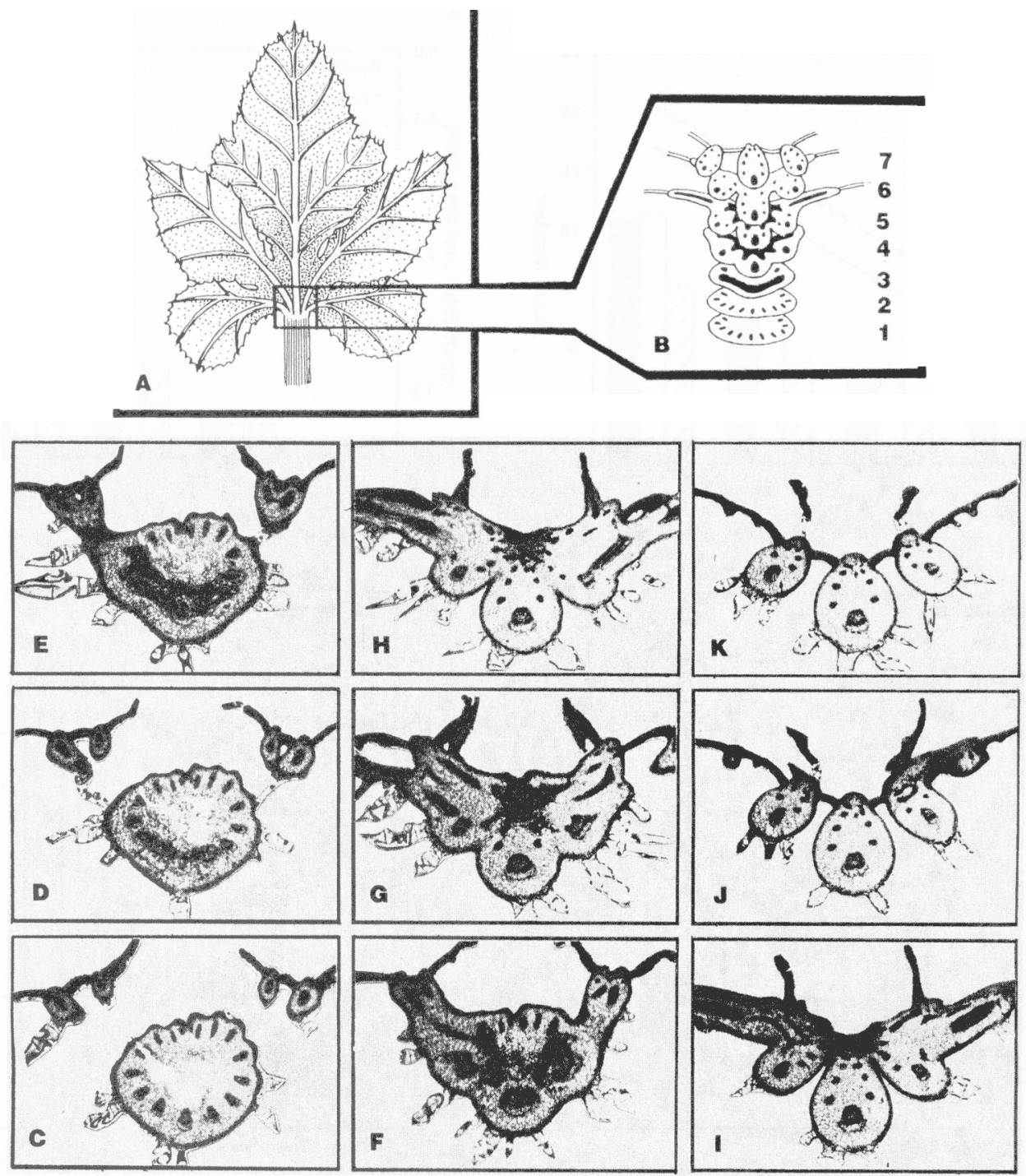

Fig. 4. Vascular tissue arrangement in the transition zone between the petiole and leaf blade for a normal Cucurbito pepo leaf. Serial cross sections at $14 \mu \mathrm{m}$ were made of leaves about $1 \mathrm{~cm}$ long, petiole and blade combined. Normal leaf abaxial view (A), vascular tissue schematic (B), serial cross-sections 0 (C), 70 (D), 140 (E), 210 (F), 280 (G), $350(\mathbf{H}), 420(\mathbf{I}), 490(\mathbf{J})$, and $560(\mathbf{K}) \mu \mathrm{m}$ from the petiole-leaf blade junction.

the last pair of flanking bundles diverges into secondary veins before invagination is complete (Fig. $5 \mathrm{M}$, and $\mathrm{N}$ ). As in $\mathrm{N}$ leaves, further branching into the remaining secondaries is accompanied by the divergence of the most adaxial bundles in each vein followed by the division and divergence of the large abaxial vascular bundle. Vein fusion results from the delay of vein formation rather than the cohesion of formed structures.

Presumptive cause of fused vein structure. In typical dicot leaf development (Fahn, 1990), the leaf blade results from lateral marginal meristem activity along the sides of the elongating leaf axis, followed by plate meristem activity in the expanding lamina. Development of the midrib and its vascular system generally precedes lamina expansion. Differential growth of the marginal meristem creates leaf lobes, while repression of marginal meristem activity forms petioles.

The anatomy of the FV trait suggests its structure results from the distortion of the petiole-leaf blade boundary through interference in marginal meristem activity. The vascular arrangement of a FV leaf can be viewed as an intermediate between a $\mathrm{N}$ petiole and leaf blade. In the lower abaxial half of the transition zone, the central vein develops more or less normally. Vascular develop- ment, dispersal, and arrangement are similar to that of a $\mathrm{N}$ leaf, occurring with the initial invagination of the epidermis and cortex. This pattern may result from midrib formation preceding lamina expansion. In the upper adaxial half of the transition zone, however, the secondary dispersal of vascular tissue forms a partial ring of bundles similar to that of the petiole. The bundles are large, equidistant and peripheral. Their dispersal occurs as the coalesced complex of vascular tissue relocates adaxially. This difference between abaxial and adaxial vascular development implies that marginal meristem activity is repressed in the adaxial portion of the transition zone. Repression subsequently prevents the localized formation and activity of plate meristems, thus causing the absence or reduction of interveinal leaf blade. Repression is incomplete, however, because the lamina develops to the outside of the outer lateral veins.

Interference of marginal meristem activity is further implicated by the similarity between leaf lobe configuration and FV expression. The first true leaves of $C$. pepo have three shallow lobes. As leaf number increases five lobes are produced and the leaf sinuses deepen (Whitaker and Davis, 1962). FV expression has a similar temporal pattern; expression is delayed until the 


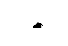

$\mathbf{A}$
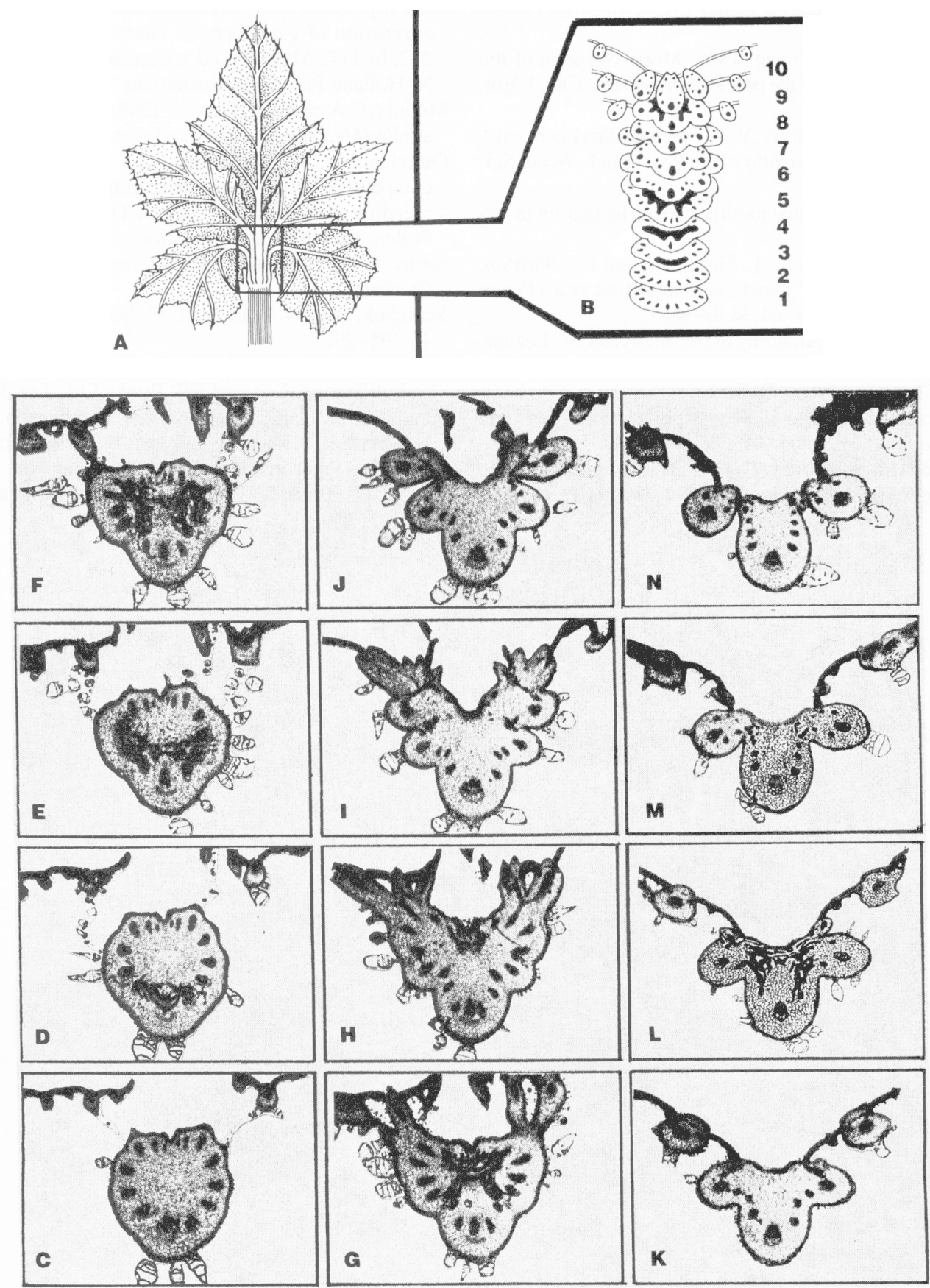

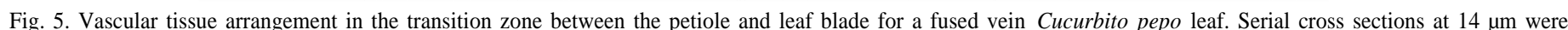

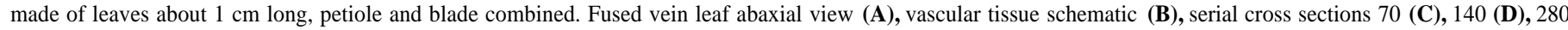
(E), $350(\mathbf{F}), 420(\mathbf{G}), 490(\mathbf{H}), 560(\mathbf{I}), 700(\mathbf{J}), 840(\mathbf{K}), 910(\mathbf{L}), 980(\mathbf{M})$, and 1050 (N) $\mu$ m from the petiole-leaf blade junction.

fourth to tenth leaf and vein fusion increases with leaf number. The greatest vein fusion was observed in FV segregants with the deepest leaf lobes.

An epigenetic model of plant patterning asserts that meristem activities are induced, determined, and maintained through a cascade of decreasing developmental options in response to competing molecular signals (Sachs, 1991). Work with leaf mutants in Pisum sativum has shown that the compartmentalization of leaves into stipules, leaflets, and tendrils results from homeotic gene control of the size, growth, and division of leaf meristems (Gould et al., 1986; Marx, 1987, Meicenheimer et al., 1983; Young, 1983). Accordingly, the FV trait may disrupt the petiole-leaf blade boundary in $C$. pepo by altering the distribution of a signal or signals responsible for marginal meristem activity. Instead of repression ending at presumptive petiole-leaf blade juncture, it extends into the leaf blade, where competition with signals for midrib development result in FV formation.

\section{Literature Cited}

Carle, R.B. and J.B. Loy. 1991. Fused vein trait in Cucurbita pepo L. Cucurbit Genet. Coop. Rpt. 14:111-112.

Carle, R.B. and J.B. Loy. 1996a. Genetic analysis of the fused vein trait in Cucurbita pepo L. J. Amer. Soc. Hort. Sci. 121: 13-17.

Carle, R.B. and J.B. Loy. 1995b. Fused vein trait in Cucurbita pepo L. associated with subvitality of the male gametophyte. J. Amer. Soc. Hort. Sci.121:18-22. 
Fahn, A. 1990. Plant anatomy, 4th ed. Pergamon Press, Maxwell House, New York. p. 208-252,411453.

Gould, K. S., E.G. Cutter, and J.P. Young. 1986. Morphogenesis of the compound leaf in three genotypes of the pea, Pisum sativum. Can. J. Bet. 64:1268-1276.

Jensen, W.A. 1962. Botanical histochemistry. W.H. Freeman, San Francisco.

Mains, E.B. 1950. Inheritance in Cucurbita pepo. Proc. Mich. Acad. Sci. Arts Let. 36:27-30.

Marx, G.A. 1987. A suite of mutants that modify pattern formation in pea leaves. Plant Mol. Biol. 5:311-335.

Meicenheimer, R. D., F.J. Muehlbauer, J.L. Hindman, and E.T. Gritton. 1983. Meristem characteristics of genetically modified pea (Pisum sativant) leaf primordia. Can. J. Bet. 61:3430-3447.

Metcalfe, C.R. and L. Chalk. 1950. Anatomy of the dicotyledons: Leaves, stem, and wood in relation to taxonomy with notes on economic uses, vol. 1., p. 684-691. Clarendon Press, Oxford.

Mulcahy, D.L. 1974. Correlation between speed of pollen tube growth and seedling height in Zea mays L. Nature 249:491-493.

Mulcahy, D.L. and G.B. Mulcahy. 1975. The influence of garnetophytic competition on sporophytic quality in Dianthus chinensis. Theoret. Appl. Genet. 46:277-280.
Mulcahy, D. L., G.B. Mulcahy, and E. Ottaviano. 1975. Sporophytic expression of gametophytic competition in Petunia hybrida, p. 227232. In: D.L. Mulcahy (ed.). Gamete competition in plants and animals. N. Holland Pub. Co., Amsterdam.

Mulinix, C.A. and A.F. Iezzoni. 1988. Microgametophytic selection in two alfalfa (Medicago sativa L.) clones. Theor. Appl. Genet. 75:917-922.

Ottaviano, E., M. Sari-Gorla, and I. Arenare. 1983. Male gametophytic competitive ability in maize selection and implications with regard to breeding systems,p. 367-374. In: D.L. Mulcahy and E. Ottaviano (eds.). Pollen: Biology and implications plant breeding. Elsevier, New York.

Sachs, T. 1991. Pattern formation in plant tissues. Cambridge Univ. Press, Cambridge.

Scarchuk, J. 1954. Fruit and leaf characters in summer squash. J. Hered. 45:295-297.

Whitaker, T.W. and G.N. Davis. 1962. Cucurbits-Botany, cultivation, and utilization. Leonard Hill Books Ltd., London.

Windsor, J. A., L.E. Davis, and A.G. Stephenson. 1987. The relationship between pollen load and fruit maturation and the effect on pollen load on offspring vigor in Cucurbita pepo. Amer. Nat. 129:643-656.

Young, J.P.W. 1983. Pea leaf morphogenesis: A simple model. Ann. Bet. 52:311-316. 